\section{Military Technical College Kobry El-Kobbah, Cairo, Egypt}

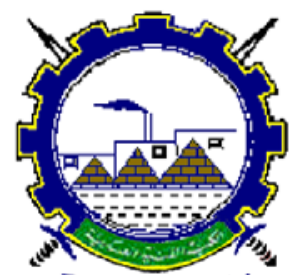

I.C.E.E.2014 $7^{\text {th }}$ International Conference

on

Chemical \& Environmental

Engineering

27 - 29 May, 2014.

(CEED-4)

\title{
Elemental mass size distributions of atmospheric aerosol particles Mona Moustafa ${ }^{*}$, Amer Mohamed, Abdel-Rahman Ahmed and Hyam Nazmy
}

\begin{abstract}
:
Outdoor aerosol particles were characterized in industrial area of Samalut city (ElMinia/Egypt) using low pressure Berner cascade impactor as an aerosol sampler. The impactor operates at $1.7 \mathrm{~m}^{3} / \mathrm{h}$ flow rate. Seven elements were investigated including Ca, Ba, $\mathrm{Fe}, \mathrm{K}, \mathrm{Cu}, \mathrm{Mn}$ and $\mathrm{Pb}$ using atomic absorption technique. The mean mass concentrations of the elements ranged from $0.42 \mathrm{ng} / \mathrm{m}^{3}$ (for $\mathrm{Ba}$ ) to $89.62 \mathrm{ng} / \mathrm{m}^{3}$ (for $\mathrm{Fe}$ ). The mass size distributions of the investigated elements were bi-modal log normal distribution corresponding to the accumulation and coarse modes.
\end{abstract}

Keywords:

Mass concentration, aerosol particles, size distribution.

* Physics Department, Faculty of Science, Minia University, Minia/Egypt Corresponding Author: Mona_moustafa9@yahoo.com

(Mobile: 01229334748) 


\section{Introduction}

In recent years, aerosols have received increasing attention due to the roles they play in many climate and environmental processes. Size and chemical composition of atmospheric particles are important parameters in several processes occurring in the atmosphere, [1]. For instance, visibility reduction, cloud and fog formation, particle growth and gas-particle interactions, [2]. Particles also have adverse health effects depending strongly on their size, specific surface area, number and chemical composition that regulate the toxicity of any specific element. In addition to the environmental and health effects of aerosol particles they also can cause corrosion and damage to materials and works of architecture and arts.

Metals are commonly found in atmospheric particles. While they can be present in almost all sizes of atmospheric particulate, in general, fine particulate carries higher concentrations of toxic metals than coarse particulate, $[3,4]$. Metals associated with respirable particles have been shown to increase numerous diseases, [5, 6]. Metals in the urban atmosphere are frequently associated with specific pollutant sources, and these are often used as tracers in order to identify the source of atmospheric particulate, [7, 8, 9, 10].

Knowledge of the size distribution of atmospheric particles within which trace elements and metals reside is not only vital in understanding particulate matter effects on human health, but also controls the extent to which metals may be dispersed via atmospheric transport and hence is a prerequisite for the determination of rates of deposition of metals to the Earth's surface, [11].

The dispersion and accumulation of particulate matter in any location is mainly affected by the existing sources, meteorological conditions and local topography, [12]. Atmospheric aerosol dispersion in industrial zones has received little attention. Therefore, the objectives of this study were to investigate the mass concentration and mass size distribution of elements in the aerosols at industrial area of Samalut in El-Minia governorate (Upper Egypt).

\section{Methodology}

In the present work a low pressure Berner cascade Impactor was used as an aerosol sampler to determine the mass concentration and mass size distribution of atmospheric aerosols. Measurements were performed from August 2012 to January 2013. Three or four runs were conducted in each month. The sampling time of each run is $6 \mathrm{~h}$. The samples are collected at the quarry private iron and steel company closed to cement factory in Samalut (latitude: $\mathrm{N} 28^{\circ}$ $18 \backslash 30 \backslash$, longitude: E $\left.30^{\circ} 42 \backslash 28 \backslash \backslash\right)$. The site represents an industrial area surrounded from the east by mountains. These mountains are formed with limestone rocks and have elevation of about $20 \mathrm{~m}$. The impactor contains eight size fractionating stages and operates at a flow rate of $1.7 \mathrm{~m}^{3} \mathrm{~h}^{-1}$. The cut-off diameters of the impactor stages are 82, 157, 270, 650, 1110, 2350, 4250 and $5960 \mathrm{~nm}$. Cut-off diameter is defined as the particle size that gives $50 \%$ of the collection efficiency. An accurate method of the impactor was calibrated in the isotope laboratory Gottingen University, Germany, [13]. Figures (1) and (2) show aerosol sampling and the components of an impactor stage.

The samples collected by low pressure Berner cascade impactor were analyzed by atomic absorption spectroscopy for seven elements including Lead (Pb), Manganese (Mn), Iron ( $\mathrm{Fe}$ ), Copper $(\mathrm{Cu})$,Potassium $(\mathrm{K})$, Calcium $(\mathrm{Ca})$ and Barium $(\mathrm{Ba})$. The sample was cut into small pieces. $5 \mathrm{ml}$ diluted $\mathrm{HCl}$ was added to the sample (1:1) and gently heated on hotplate till complete dissolution. Few drops of HNO3 are added to the solution. The solution is 
transferred to auto sampler cup and completed to $10 \mathrm{~mL}$ deionized water. (National Institute for Standards, NIS-Egypt).

Meteorological parameters (temperature and relative humidity) were recorded by Hi 8564 thermo hygrometer during the sampling. The temperature varied between 30 to $39{ }^{0} \mathrm{C}$ with mean value $36{ }^{0} \mathrm{C}$ while relative humidity varied between 18 to $42 \%$ with mean value $32 \%$. Samples collected under abnormal weather conditions were canceled.

Gravimetric analysis of the samples was conducted by Mettler analytical AE240 Dual Range Balance to get the collected mass of the aerosol particles on the substrates.

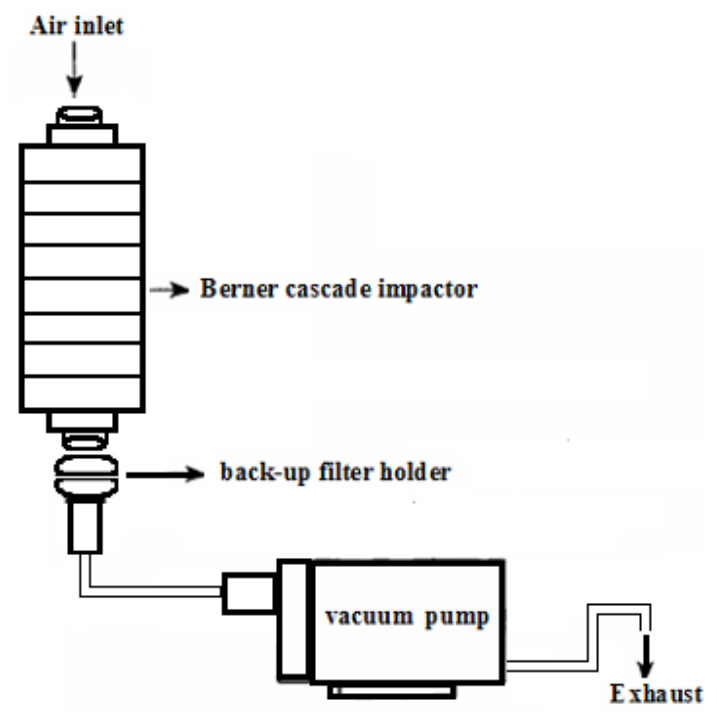

Fig. 1. Aerosol sampling using Berner impactor

Knowing the mass of the collected particles, the flow rate of the impactor and the sampling time, mass concentrations of aerosol particles were calculated as follows:

$$
v=\frac{m}{Q . t} \ldots \ldots \ldots . . . \mu g / m^{3}
$$

Where

$v$ is The specific mass concentration

$\mathrm{m}$ is the total deposited aerosol mass on the impactor stages $(\mu \mathrm{g})$.

$\mathrm{Q}$ is the impactor flow rate $\left(\mathrm{m}^{3} / \mathrm{h}\right)$.

$\mathrm{t}$ is the sampling time (hour). 

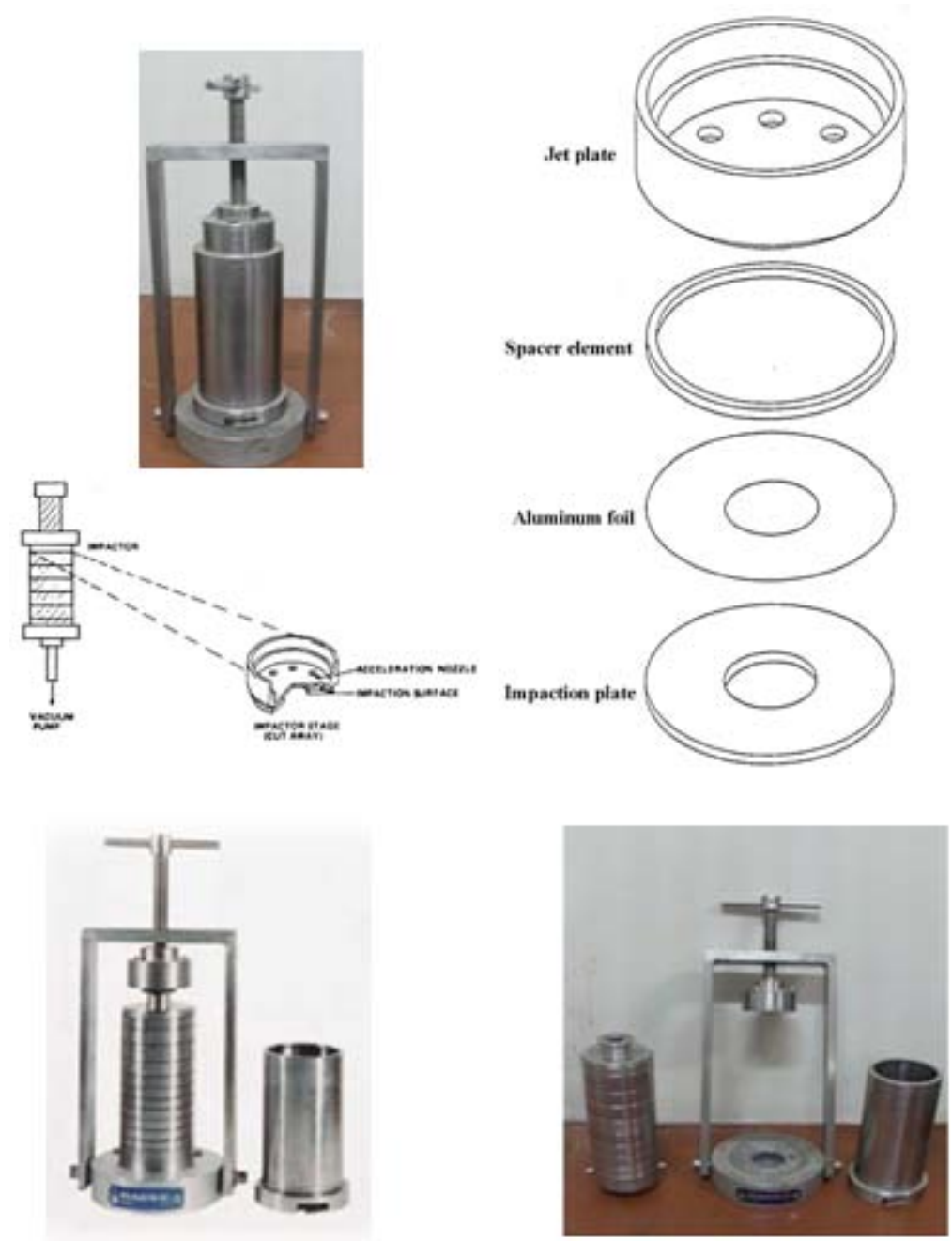

Fig. 2. Berner cascade impactor and stage components

The parameters of the mass size distribution, Mass Median Aerodynamic Diameter (MMAD) and Geometric Standard Deviation (GSD) were given by the following equations, [14].

$$
\begin{gathered}
\ln M M A D=\frac{\sum n_{i} \ln d_{i}}{\sum n_{i}} \\
\ln (G S D)=\left[\frac{\sum n_{i}\left(\ln d_{i}-\ln M M A D\right)^{2}}{\Sigma n_{i}}\right]^{\frac{1}{2}}
\end{gathered}
$$

Where MMAD is the Mass Median Diameter, $n_{i}$ is the fraction in stage $i, d_{i}$ is the cutoff diameter of the stage $\mathrm{i}$ and GSD is the Geometric Standard Deviation. MMAD is defined as 
the diameter at $50 \%$ cumulative fractions. GSD of the size distribution is defined as the diameter at $84 \%$ cumulative mass divided by the diameter obtained at $50 \%$.

\section{Results and discussion}

\subsection{Elemental mass size distribution of aerosols}

Mass size distributions of individual elements are presented in Figures (3) to (9). The distributions of the investigated elements $[\mathrm{Pb}, \mathrm{Mn}, \mathrm{Fe}, \mathrm{Cu}, \mathrm{K}, \mathrm{Ca}$ and $\mathrm{Ba}$ ] are bi-modal log normal distribution corresponding to the accumulation and coarse modes. Accumulation mode, consisting of long-lived particles of sizes of a few tenths of a micrometer $(100 \mathrm{~nm}<$ $\mathrm{Dp}<2000 \mathrm{~nm}$ ). Particles in this mode are forming by gas to particle conversion, chemical reactions, condensation and coagulation. While the particles in te coarse mode ( $\mathrm{Dp}>2000$ $\mathrm{nm}$ ) are generated by mechanical processes such as sea spray, erosion, and resuspension and are removed by sedimentation and washout. This mode contains windblown dust, sea salt spray, and plant materials. The coarse particles are characterized by a high deposition velocity and they have short residence times. The residence time of aerosols depends on their size, chemistry and height in the atmosphere. The atmospheric aerosol size distributions are almost bi-modal. The modal size and composition are variable, depending on the nature of the surface cover and atmospheric condition, specially the wind speed. The bimodal nature of elements size distribution been reported for different industrial sites, [12, 15].

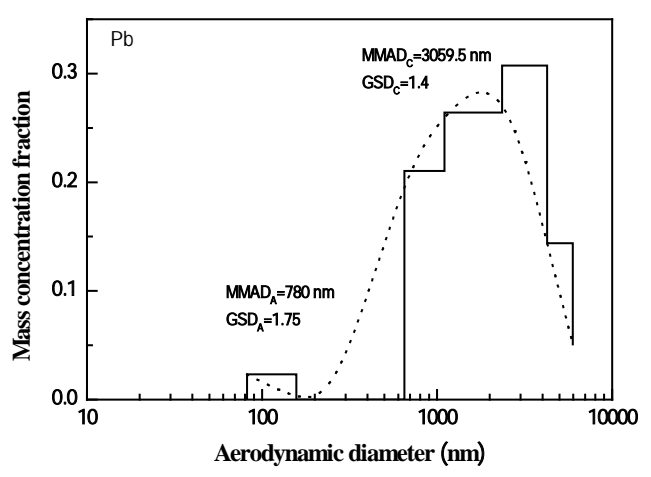

Fig. 3. Mass size distribution of $\mathrm{Pb}$ at industrial area of Samalut (El-Minia)

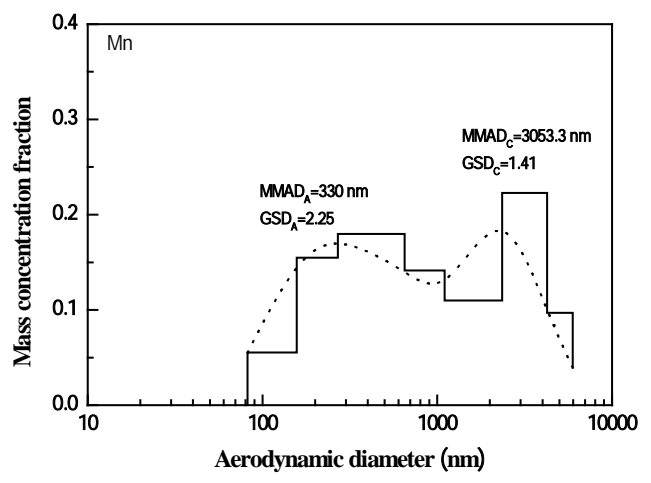

Fig. 4. Mass size distribution of Mn at industrial area of Samalut (El-Minia) 


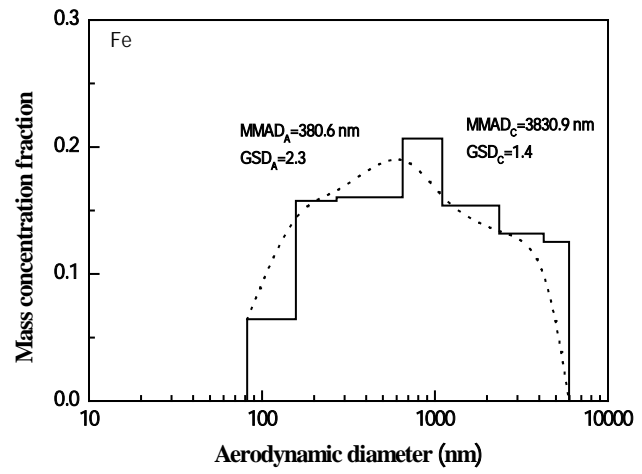

Fig. 5. Mass size distribution of Fe at industrial area of Samalut (El-Minia)

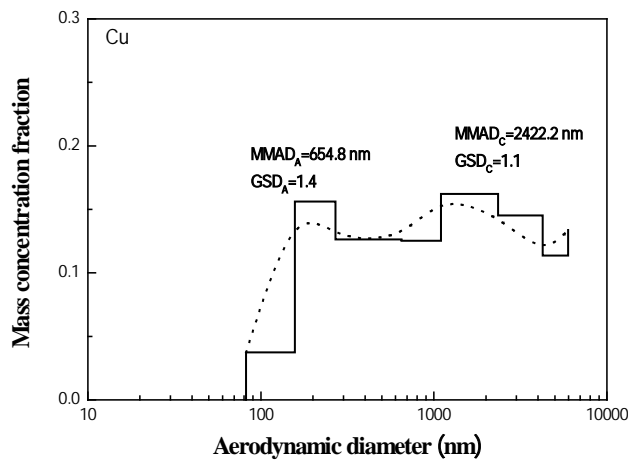

Fig. 6. Mass size distribution of Cu at industrial area of Samalut (El- Minia)

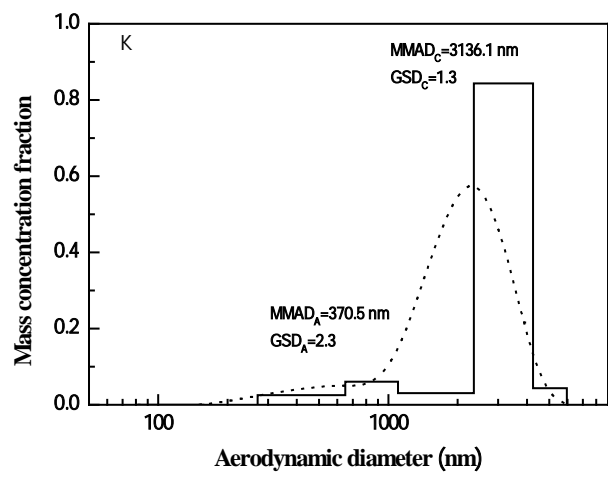

Fig. 7. Mass size distribution of $\mathrm{K}$ at industrial area of Samalut (El-Minia) 


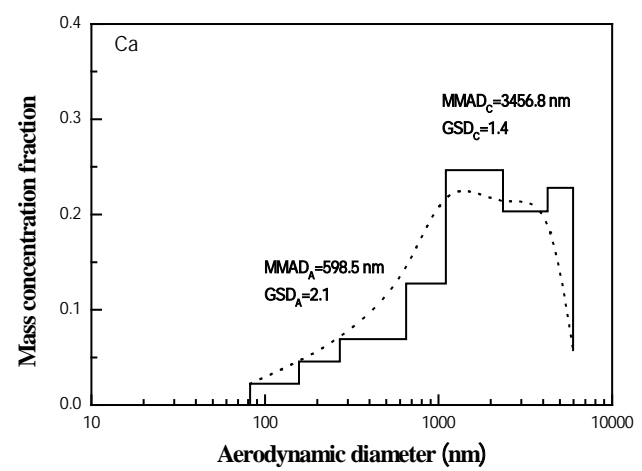

Fig. 8. Mass size distribution of Ca at industrial area of Samalut (El-Minia)

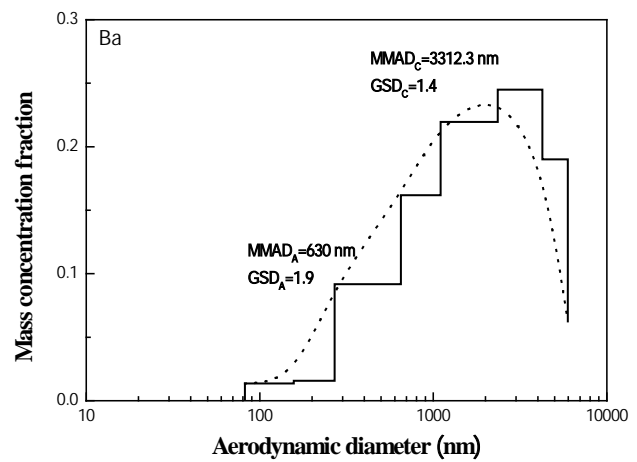

Fig. 9. Mass size distribution of Ba at industrial area of Samalut (El-Minia)

The lowest mass median aerodynamic diameter of the accumulation mode, $\mathrm{MMAD}_{\mathrm{A}}(330$ $\mathrm{nm}$ ) is found for $\mathrm{Mn}$ with a geometric standard deviation, $\mathrm{GSD}_{\mathrm{A}}$ of 2.25 while $\mathrm{Pb}$ has the highest $\mathrm{MMAD}_{\mathrm{A}}(780 \mathrm{~nm})$ with a $\mathrm{GSD}_{\mathrm{A}}$ of 1.75 . $\mathrm{Cu}$ has the lowest mass median aerodynamic diameter in the coarse mode, $\operatorname{MMAD}_{\mathrm{C}}(2422.2 \mathrm{~nm})$ with a $\mathrm{GSD}_{\mathrm{C}}$ of 1.1 while $\mathrm{Fe}$ has the highest $\mathrm{MMAD}_{\mathrm{C}}(3830.9 \mathrm{~nm})$ with a $\mathrm{GSD}_{\mathrm{C}}$ of 1.4. These parameters are essential for the calculation of particles deposition in the human lung.

The mass size distribution of $\mathrm{Pb}$ is mostly concentrated in the accumulation mode (650-1100 $\mathrm{nm})$ and coarse mode $(2350 \mathrm{~nm})$. Mn distribution shifts to lower size in the accumulation mode (157-650 nm) and it is concentrated at the same size $(2350 \mathrm{~nm})$ of coarse mode.

The mass size distributions of $\mathrm{Fe}$ and $\mathrm{Cu}$ are mostly concentrated in the accumulation mode $(157-1100 \mathrm{~nm})$ and coarse mode $(2350-4250 \mathrm{~nm})$ for Fe and shifts to higher size at $5960 \mathrm{~nm}$ for $\mathrm{Cu}$.

The mass size distributions of $\mathrm{Ca}$ and $\mathrm{Ba}$ are mostly concentrated in the accumulation mode $(650-1100 \mathrm{~nm})$ and coarse mode $(2350-4250 \mathrm{~nm})$. K is mostly concentrated at the coarse mode (2350 $\mathrm{nm})$.

These distributions suggesting that the natural crustal sources, i.e. dust mountains, contribute the industrial sources for the emission of the elements.

It can be seen that the elements in the accumulation mode are more distributed $\left(2.25 \geq \mathrm{GSD}_{\mathrm{A}} \geq 1.4\right)$ than the elements in the coarse mode $\left(1.14 \geq \mathrm{GSD}_{\mathrm{C}} \geq 1.41\right)$. This could be 
attributed to the difference of aerosols origins and the variation of their residence time in the atmosphere.

\subsection{Elemental mass concentration of aerosols}

Average mass concentrations of the elements are shown in Figure (10). The mean concentration ranged from $0.42 \mathrm{ng} / \mathrm{m}^{3}$ to $89.62 \mathrm{ng} / \mathrm{m}^{3}$. Aerosol concentrations varied depending on local sources and meteorological conditions. The highest concentration is obtained for Fe $\left(89.62 \mathrm{ng} / \mathrm{m}^{3}\right)$ followed by $\mathrm{K}\left(25.65 \mathrm{ng} / \mathrm{m}^{3}\right), \mathrm{Cu}\left(2.99 \mathrm{ng} / \mathrm{m}^{3}\right), \mathrm{Mn}(2.09$ $\left.\mathrm{ng} / \mathrm{m}^{3}\right), \mathrm{Pb}\left(1.68 \mathrm{ng} / \mathrm{m}^{3}\right)$ followed by Ca $\left(0.52 \mathrm{ng} / \mathrm{m}^{3}\right)$ and the lowest is Ba $\left(0.42 \mathrm{ng} / \mathrm{m}^{3}\right)$.

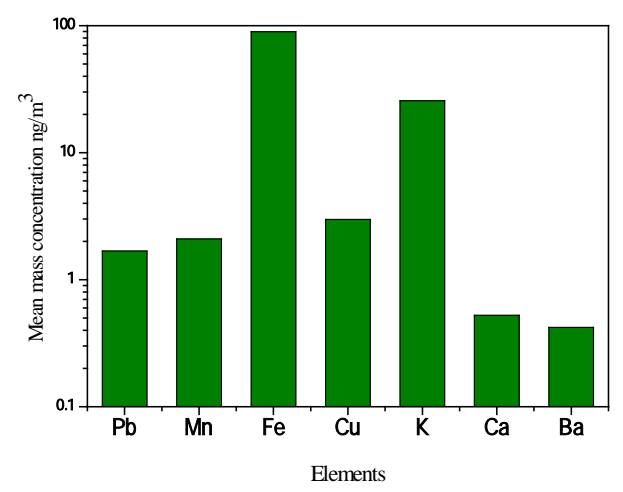

Fig. 10. Mass concentration of elements in aerosols at industrial area of Samalut

$\mathrm{Fe}, \mathrm{Mn}$ and $\mathrm{Pb}$ were associated with natural and industrial-related elements suggesting both origins. The possible industrial sources of $\mathrm{Fe}$ and $\mathrm{Mn}$ are ferromanganese production plants, steel and cement industries, [16, 17]. Another possible sources of Fe are motor vehicle emissions, Re-suspended soil, traffic and Heavy oil combustion, [18, 19$]$.

\section{Conclusion}

In this study, characteristics of aerosol particles were reported in industrial area of Samalut city (El-Minia/Egypt) using low pressure Berner cascade impactor as an aerosol sampler. Seven elements were investigated including $\mathrm{Ca}, \mathrm{Ba}, \mathrm{Fe}, \mathrm{K}, \mathrm{Cu}, \mathrm{Mn}$ and $\mathrm{Pb}$ using atomic absorption technique. The mean mass concentrations of the elements ranged from $0.42 \mathrm{ng} / \mathrm{m}^{3}$ to $89.62 \mathrm{ng} / \mathrm{m}^{3}$. The highest concentration is obtained for Fe $\left(89.62 \mathrm{ng} / \mathrm{m}^{3}\right)$ followed by $\mathrm{K}$ $\left(25.65 \mathrm{ng} / \mathrm{m}^{3}\right), \mathrm{Cu}\left(2.99 \mathrm{ng} / \mathrm{m}^{3}\right), \mathrm{Mn}\left(2.09 \mathrm{ng} / \mathrm{m}^{3}\right), \mathrm{Pb}\left(1.68 \mathrm{ng} / \mathrm{m}^{3}\right), \mathrm{Ca}\left(0.52 \mathrm{ng} / \mathrm{m}^{3}\right)$ and the lowest is $\mathrm{Ba}\left(0.42 \mathrm{ng} / \mathrm{m}^{3}\right)$. The mass size distributions of the investigated elements were bimodal log normal distribution corresponding to the accumulation and coarse modes.

\section{References}

[1] Ellouz, F., Masmoudi, M., Quisefit, J.P. and Medhioub, K., "Characteristics of trace elements in aerosols collected in Northern Tunisia," ”, Physics and Chemistry of the Earth,” 55 -57, 2013, pp. 35-42.

[2] Seinfeld, J. H. and Pandis, S. N., "Atmospheric chemistry and physics from air pollution to climate change," ", Wiley, New York,” 1998, pp. 901-912. 
[ 3] Fang, G. C. and Huang, C. S., “Atmospheric particulate and metallic elements (Zn, Ni, $\mathrm{Cu}, \mathrm{Cd}$ and $\mathrm{Pb}$ ) size distribution at three characteristic sampling sites," ”, EnvironmentalForensics,” 12-3, 2011, pp. 191-199. http://dx.doi.org/10.1080/15275922.2011.595052.

[4] Hieu, N. T. and Lee, B. K., "Characteristics of particulate matter and metals in the ambient air from a residential area in the largest industrial city in Korea,”,", Atmospheric Research,” 98(2-4), 2010, pp. 526-537. http://dx.doi.org/10.1016/j.atmosres.2010.08.019.

[ 5] Hu, X., Zhang, Y., Ding, Z., Wang, T., Lian, H., Sun, Y. and Wu, J., “Bioaccessibility and health risk of arsenic and heavy metals (Cd, Co, Cr, Cu, Ni, Pb, Zn and $\mathrm{Mn}$ ) in TSP and PM2.5 in Nanjing, China,” ”, Atmospheric Environment,” 57, 2012, pp.146152.

http://dx.doi.org/10.1016/j.atmosenv.2012.04.056.

[ 6] Pandey, P., Patel, D. K., Khan, A. H., Barman, S. C., Murthy, R. C. and Kisku, G. C., "Temporal distribution of fine particulates (PM 2.5, PM 10), potentially toxic metals, PAHs and Metal-bound carcinogenic risk in the population of Lucknow City, India,” ", Journal of Environmental Science and Health - Part A Toxic/Hazardous Substances and Environmental Engineering," 48-7,2013, pp. 730-745.

http://dx.doi.org/10.1080/10934529.2013.744613.

[ 7] Weckwerth, G., "Verification of traffic emitted aerosol components in the ambient air of Cologne (Germany),” ”, Atmospheric Environment,” 35-32, 2001, pp. 5525-5536. http://dx.doi.org/10.1016/S1352-2310.

[ 8] Chen, B., Stein, A. F., Maldonado, P.G., Sanchez de la Campa, A. M., GonzalezCastanedo, Y., Castell, N. and de la Rosa, J. D., "Size distribution and concentrations of heavy metals in atmospheric aerosols originating from industrial emissions as predicted by the HYSPLIT model," ”, Atmospheric Environment," 71, 2013, pp. 234244. http://dx.doi.org/10.1016/j.atmosenv.2013.02.013.

[9] Duan, J., and Tan, J., Atmospheric heavy metals and Arsenic in China: Situation, sources and control policies,”", Atmospheric Environment,” 74, 2013, pp. 93-101. http://dx.doi.org/10.1016/j.atmosenv.2013.03.031.

[10] Wang, Q., Bi, X. H., Wu, J. H., Zhang, Y. F. and Feng, Y. C., "Heavy metals in urban ambient PM10 and soil background in eight cities around China,”, Environmental Monitoring and Assessment,” 185-2,2013, pp. 1473-1482.

http://dx.doi.org/10.1007/s10661-012-2646-5.

[11] Allen, A.G., Nemitz, E., Shi, J.P., Harrison, R.M. and Greenwood, J.C., "Size distributions of trace metals in atmospheric aerosols in the United Kingdom,” ”, Atmospheric Environment,” 35, 2001, pp. 4581-4591.

[12] Aryal, R., Kim, A., Kyu Lee, B., Kamruzzaman, M. and Beecham, S., “characteristics of atmospheric particulate matter and metals in industrial sites in Korea," ”, Environment and Pollution,” 2- 4, 2013, pp. 10-21.

[13] Reineking, A., Scheibel, H. G., Hussin, A., Becker, K. H. and Porstendörfer, J., "Measurements of Stage Efficiency Functions Including Interstage Losses for Sierra and Berner Impactor and Evaluation of Data by Modified Simplex Method,” ”, Journal of Aerosol Science,” 15, 1984, pp. 376. 
[14] Hinds, W. C. (ed.), Aerosol technology, properties, Behavior, and measurement of airborne particles, $2^{\text {rd }}$. ed., Vol. 1, Wiley, New York, 1999, pp. 74-108.

[15] Toscano, G., Moret, I., Gambaro, A., Barbante , C. and Capodaglio , G., "Distribution and seasonal variability of trace elements in atmospheric particulate in the Venice Lagoon,” ”, Chemosphere,” 85,2011, pp. 1518-1524.

[16] Alleman, L.Y., Lamaison, L., Perdrix, E., Robache, A. and Galloo, J.C., "PM10 metal concentrations and source identification using positive matrix factorization and wind sectoring in a French industrial zone,” ”, Atmospheric Research,” 96,2010, pp. 612625.

[17] Tran, D.T., Alleman, L., Coddeville, Y.P. and Galloo, J., "Elemental characterization and source identification of size resolved atmospheric particles in French classrooms," ”, Atmospheric Environment," 54, 2012, pp. 250-259.

[18] Cuccia, E., Bernardoni, V., Massabo, D., Prati, p., Valli, G. and Vecchi, R., “An alternative way to determine the size distribution of airborne particulate matter," ”, Atmospheric Environment," 44, 2010, pp. 3304-3313.

[19] Khodeir, M., Shamy, M., Alghamdi, M., Zhong, M., Sun, H., Costa, M., Chen, L.-C. and Maciejczyk, P., "Source apportionment and elemental composition of PM2.5 and PM10 in Jeddah City, Saudi Arabia,” ”, Atmospheric Pollut. Res,” 3, 2012, pp. 331340. 